\title{
Correction to: Randomized Algorithms for Tracking Distributed Count, Frequencies, and Ranks
}

\section{Zengfeng Huang $^{1}\left(\mathbb{D} \cdot \mathrm{Ke} \mathrm{Yi}^{2} \cdot\right.$ Qin Zhang $^{3}$}

Published online: 28 July 2020

(c) Springer Science+Business Media, LLC, part of Springer Nature 2020

\section{Correction to: Algorithmica (2019) 81:2222-2243 https://doi.org/10.1007/s00453-018-00531-y}

After publication of the article [1] the authors have noticed that the funding information are not published in online and print version of the article. The omitted funding acknowledgement is given below.

Funding This study was funded by, Shanghai Science and Technology Development Foundation (18YF1401200) and National Natural Science Foundation of China (61802069) to Zengfeng Huang. Research Grants Council, University Grants Committee (HK) (GRF-621413, GRF-16211614, and GRF16200415 ) to Ke Yi. National Science Foundation (NSF CCF-1844234) to Qin Zhang.

\section{Reference}

1. Huang, Z., Yi, K., Zhang, Q.: Randomized algorithms for tracking distributed count, frequencies, and ranks. Algorithmica 81, 2222-2243 (2019). https://doi.org/10.1007/s00453-018-00531-y

Publisher's Note Springer Nature remains neutral with regard to jurisdictional claims in published maps and institutional affiliations.

The original article can be found online at https://doi.org/10.1007/s00453-018-00531-y.

Zengfeng Huang

huangzf@fudan.edu.cn

$\mathrm{Ke} \mathrm{Yi}$

yike@cse.ust.hk

Qin Zhang

qzhangcs@indiana.edu

1 School of Data Science, Fudan University, Shanghai, China

2 The Hong Kong University of Science and Technology, Clear Water Bay, Hong Kong

3 Indiana University Bloomington, Bloomington, USA 